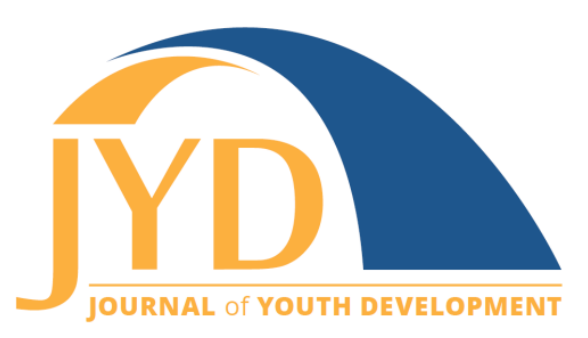

http://jyd. pitt. edu/ | Vol. 14 Issue 3 DOI 10.5195/jyd.2019.740 | ISSN 2325-4017 (online)

\title{
Using the Delphi Technique to Determine Challenges Facing Oklahoma's 4-H Program
}

\author{
Kristin Young \\ Oklahoma State University, 4-H Youth Development \\ kristin.young@okstate.edu
}

Jeff Sallee

Oklahoma State University, 4-H Youth Development

jeff.sallee@okstate.edu

Jon Ramsey

Oklahoma State University, Agricultural Education, Communications, and Leadership

jon.ramsey@okstate.edu

\section{Dwayne Cartmell}

Oklahoma State University, Agricultural Education, Communications, and Leadership dwayne.cartmell@okstate.edu

\begin{abstract}
As youth development organizations continue to evolve and grow, professionals are faced with the challenges to address the ever-changing needs of their clientele. In order to maintain the longevity of the Oklahoma 4-H program, Extension professionals must address challenges prohibiting, discouraging, or discontinuing participation of youth, families, and volunteers in the program. Additionally, state administrators should examine the challenges their staff face in efforts to execute the mission of 4-H Youth Development. A modified Delphi technique was employed in this study to determine the challenges facing Oklahoma 4-H. Two expert panels were used in this study: Extension educators and 4-H volunteers (Panel 1) and 4-H parents (Panel 2). After 3 rounds of the Delphi technique, Panel 1 identified 11 challenges and Panel 2 identified 9 challenges facing Oklahoma 4-H in the next 5 years. There were 8 identical challenges identified by both panels. These 8 challenges represent priorities for Oklahoma 4-H to address. This study could be replicated in any state to confirm the challenges facing youth development organizations. This research study indicates these findings may be widespread and affect other youth development organizations across the nation beyond the Oklahoma 4-H program.
\end{abstract}

Key words: Delphi technique, 4-H, challenges, research methods

(c) $\mathbf{E Y}$ New articles in this journal are licensed under a Creative Commons Attribution 4.0 License. This journal is published by the University Library System, University of Pittsburgh and is cosponsored by the University of Pittsburgh Press. The Journal of Youth Development is the official peer-reviewed publication of the National Association of Extension 4-H Agents and the National AfterSchool Association. 


\section{Introduction}

In 1909, the first Oklahoma 4-H club was organized, establishing the foundation for more than 100 years of positive youth development through the Oklahoma 4-H program (Stewart \& Scheihing, 2010). Existing as the educational youth program of the Oklahoma Cooperative Extension Service (OCES), Oklahoma 4-H is rooted in agriculture. From its early beginnings of corn, tomato, and canning clubs, Oklahoma 4-H has expanded beyond its agricultural groundwork (Stewart \& Scheihing, 2010). "4-H activities don't simply teach youth skills in agriculture and home economics, but include non-formal, experiential educational programs that teach youth valuable life skills" (Boyd, Herring, \& Briers, 1992, para. 15). 4-H members now have opportunities to pursue interests in areas such as science and technology, leadership, and health and fitness (Oklahoma 4-H, 2018a).

The 4-H program has "evolved into a complex and forward-thinking system that was unimaginable more than 100 years ago" (Borden, Perkins, \& Hawkey, 2014, para. 3). Today, nearly six million youth in rural, urban, and suburban communities are enrolled in 4-H (National 4-H Council, 2018). Specifically, more than 160,000 youth participate in Oklahoma $4-H$ activities and more than 3,000 volunteers devote their time to assist the program in executing its mission (Oklahoma 4-H, 2018b).

Borden et al. (2014) noted an increasingly large need for accountability in youth development programs. As the 4-H program has grown and evolved, Extension professionals are faced with the task to address the ever-changing needs of their clientele. Reck (1951) stated, "Changes in Extension youth programs necessarily reflect the changing needs of young people and the changing times in which they live" (p. 299). Further, Borden et al. reported the encompassing challenge to $4-\mathrm{H}$ programs is staying true to its founding mission while addressing the needs of youth in the $21^{\text {st }}$ century.

Meeting the needs of youth and families is not the only concern 4-H programs should address. Astroth (2007) proposed working in youth development organizations has become more complex and presents numerous difficulties to professionals. Extension educators reported feeling over-committed and dissatisfied with their profession, resulting in increased turnovers of staff (Feldhues \& Tanner, 2017; Harder, Gouldthorpe, \& Goodwin, 2015; Rousan \& Henderson, 1996; Strong \& Harder, 2009). Moreover, volunteers, who assist educators in implementing positive youth development, experience their own set of challenges such as maintaining satisfaction and motivation (Arnold, Dolenc, \& Rennekamp, 2009). The demand for volunteers 


\section{Delphi Technique to Identify Program Challenges}

to support 4-H continues to rise. Concomitantly, Borden et al. (2014) asserted volunteer recruitment and training are considerable challenges to address in 4-H programs.

"4-H needs to lead the way in evaluating its efforts in terms of outcomes and program quality" (Borden et al., 2014, para. 7). As Oklahoma 4-H continues as a leading youth development organization, it is imperative to identify opportunities that could support the growth of the 4-H program and address challenges faced by families, volunteers, and Extension educators. Van Horn, Flanagan, and Thomson (1999) concluded meeting challenges is crucial to solidifying 4-H's future.

\section{Purpose}

This study employed a modified Delphi technique to determine expert Oklahoma 4-H Extension educators', volunteers', and parents' perceptions of challenges facing the Oklahoma 4-H program in the next 5 years.

\section{Research Method}

Developed by Norman Dalkey and Olaf Helmer at the Rand Cooperation in the 1950s (Franklin \& Hart, 2007; Hsu \& Sandford, 2007; Mayfield, Wingenbach, \& Chalmers, 2005), the Delphi technique was first used in technology forecasting for military use (Martin \& Frick, 1998). The Delphi technique provides an organized method to gather perspectives from people with proficiency on a certain topic (Dalkey \& Helmer, 1963).

Using a series of questionnaires, the Delphi technique collects data from a selected panel in attempt to build consensus (Dalkey \& Helmer, 1963; Linstone \& Turoff, 1975). The outcome of the 3-round technique begins with the initial round generating a variety of answers, generally by asking panelists to answer one or two open-ended questions (Ludwig, 1997). Panelists provide information they believe will successfully address the question at hand (Linstone \& Turoff, 1975). In the second round, panelists are asked to "review the items summarized by the investigators based on information provided in the first round" (Hsu \& Sandford, 2007, p. 2). As the second and third round follow, individual responses converge, resulting in a more accurate and defined group response of the initial question (Dalkey, Rourke, Lewis, \& Snyder, 1972). 


\section{Delphi Technique to Identify Program Challenges}

Using the Delphi technique offers numerous benefits, such as promoting strong participation from individuals who might not otherwise be a part of a research study or are hesitant to share thoughts in a focus group or through some other data collection approach (Brady, 2015). One advantage of the Delphi technique is that it acknowledges the unique contribution of each panelist (Hanafin, 2004). "The Delphi method is not concerned with having a generalizable sample but instead seeks input from a purposive sample or individuals with specific expertise on a topic" (Brady, 2016, para. 2).

Panel selection is an important component of a successful Delphi study. Panel members must be knowledgeable on the subject in question (Brooks, 1979). A modification was used in this study to include two expert panels. Random selection is not an appropriate tool to generate a Delphi panel, and the researcher should carefully consider the knowledge of the potential participants and define the participants' expertise, characteristics, and qualifications before identifying a sample from which to recruit (Brady, 2016; Ludwig, 1997).

\section{Panel 1: Extension Educators and Volunteers}

The target population for panel one included Extension educators and 4- $\mathrm{H}$ volunteers. In some Delphi studies, "gatekeepers" help identify potential participants with a level of expertise sought by the researcher (Brady, 2016). Therefore, Extension educators were recruited based on the recommendation of their respective district 4-H program specialist in each of the four OCES districts in 2017 (Northwest, Southwest, Northeast, and Southeast). Similar to Extension educators, 4-H volunteers often implement programming and conduct 4-H activities, so they were also included in panel one. The 4- $\mathrm{H}$ volunteers were recruited based on their tenured status of serving at least 5 years in the Oklahoma 4-H program (Culp \& Schwartz, 1999) and their recognition as a county 4-H Volunteer of the Year in 2015-2016. In total, 25 educators and $254-\mathrm{H}$ volunteers were invited via email to participate. Of the 50 potential panelists identified, 23 agreed to participate ( $46 \%$ response rate).

\section{Panel 2: Parents}

The second panel's population included 4-H parents. In order to identify 4-H parents with expertise in the Oklahoma 4-H program, parents were selected if their child had been an Oklahoma 4-H member for at least 5 years and was a state project winner in 2015-2016. These parents understand the structure and expectations of the organization in order to raise 


\section{Delphi Technique to Identify Program Challenges}

successful 4-H youth. We invited 50 parents as potential panelists to take part in the study and 21 indicated their willingness to participate (40.4\% response rate).

\section{Data Collection}

The present study included three questionnaires administered to panelists through three rounds. The researcher made the decision to eliminate panelists from the study who did not complete the instrument they were provided in rounds 1 and 2. Throughout this study, both panels remained separate from each other and were administered instruments specific to each panel.

The first questionnaires solicited personal and professional characteristics of each panel and included the open-ended question: "What challenges will the Oklahoma 4-H program face in the next five years?"

The second-round questionnaires were sent electronically to panelists who completed the first round (Panel 1: $n=16$; Panel 2: $n=17$ ). Round 2 questionnaires were generated based on the responses gathered from the first questionnaires and included 13 challenge statements identified by the educator and volunteer panel and 15 challenge statements identified by the parent panel. Panelists were asked to rank their level of agreement with each challenge to the Oklahoma 4-H program in the next 5 years.

A 5-point summated scale was used (Franklin \& Hart, 2007; Smalley \& Retallick, 2011). Ratings ranged from 1 (strongly disagree) to 5 (strongly agree), with midpoint 3 (neither agree nor disagree). Comment boxes were included alongside each item for panelists to request clarification or share additional thoughts regarding the challenge statement (Ludwig, 1997).

Challenge statements that received scores of 4 or 5 by at least $75 \%$ of each panel met consensus and were identified as challenges facing the Oklahoma 4-H program in the next 5 years (Ramsey, 2009; Shinn, Wingenbach, Linder, Briers, \& Baker, 2009). Challenge statements that received scores of 4 or 5 by $51 \%-74 \%$ of the panels were included in the third questionnaires. Items that did not receive scores of 4 or 5 by $51 \%$ of the panels were removed from further consideration as a challenge to the Oklahoma 4-H program.

The third-round questionnaires were sent to panelists who completed the second round and sought to reach consensus on the remaining challenge statements among the two panels. 


\section{Delphi Technique to Identify Program Challenges}

Three remaining items were presented to the educator and volunteer panel and five items were presented to the parent panel.

Panelists were asked to rank their level of agreement with the remaining challenge statements on the 5-point summated scale. Comment boxes were incorporated with the remaining challenge statements, prompting panelists to provide additional thoughts regarding the statements (Ludwig, 1997). In total, 13 educators and volunteers serving on Panel 1 and 13 parents serving on Panel 2 completed the third-round questionnaires.

\section{Findings and Discussion}

\section{Round 1}

The intent of the first round of this study was to understand the perceived challenges facing Oklahoma 4-H in the next 5 years by an expert panel of educators and volunteers and an expert panel of 4-H parents. Rankings of the challenges identified by the two panels are shown below.

\section{Challenges identified by Panel 1}

1. Volunteer recruitment

2. Volunteer retention

3. Professional development of earlycareer educators

4. Increased workload on educators

5. Marketing and promotion

6. Budget challenges

7. Enrollment barriers

8. Rural vs. urban opportunities for youth

9. Member retention

10. Time commitment of youth

11. Competition with other activities

12. Lack of 4-H-school partnerships

13. Lack of adult engagement in youth's 4-H involvement

\section{Challenges identified by Panel 2}

1. Increased volunteer responsibility

2. Volunteer recruitment

3. Lack of professional support and leadership for educators

4. Marketing and promotion

5. Outdated image of program

6. Outdated programming

7. Adhering to National 4-H initiatives

8. Lack of adult engagement in youth's 4-H involvement

9. Family financial barriers

10. Member retention

11. Enrollment barriers

12. Time commitment of youth

13. Competition with other activities

14. Lack of 4-H-school partnerships

15. Budget challenges 
Delphi Technique to Identify Program Challenges

The challenges panelists reported varied in areas such as volunteerism, member retention, and youth's involvement in 4-H. Panelists indicated "the rapid turnover rates of new hires" and "finding new ways to motivate teens to be a part of the 4-H program" were a few of the challenges Oklahoma 4-H must overcome. One panelist said, "The 4-H program will face growth issues due to the lack of understanding the benefit of 4-H." Additionally, another panelist stated a concern for Oklahoma 4-H is, "The continual downturn of federal, state and county budgets."

\section{Round 2}

In the second round of the study, questionnaires were administered to the panelists who completed Round 1. The questionnaires prompted panelists to rank their level of agreement with the challenge statements established in Round 1 (See Tables 1 and 2).

Table 1. Challenge Statements and Agreement Percentages in Round 2: Panel 1

\begin{tabular}{|l|c|}
\hline Challenges facing the Oklahoma 4-H Program in the next 5 years & \% Agreement \\
\hline Volunteer recruitment & $92.3 \%$ \\
\hline Marketing and promotion & $92.3 \%$ \\
\hline Budget challenges & $92.3 \%$ \\
\hline Enrollment barriers & $92.3 \%$ \\
\hline Member retention & $92.3 \%$ \\
\hline Competition with other activities & $92.3 \%$ \\
\hline Lack of adult engagement in youth's 4-H involvement & $92.3 \%$ \\
\hline Lack of 4-H-school partnerships & $84.6 \%$ \\
\hline Time commitment of youth & $76.9 \%$ \\
\hline Volunteer retention & $69.2 \%$ \\
\hline Increased workload on educators & $69.2 \%$ \\
\hline Professional development of early-career educators & $53.9 \%$ \\
\hline Rural vs. urban opportunities & $46.2 \%$ \\
\hline
\end{tabular}


Journal of Youth Development | http://jyd.pitt.edu/ | Vol. 14 Issue 3 DOI 10.5195/jyd.2019.740

Delphi Technique to Identify Program Challenges

Table 2. Challenge Statements and Agreement Percentages in Round 2: Panel 2

\begin{tabular}{|l|c|}
\hline Challenges facing the Oklahoma 4-H Program in the next 5 years & $\%$ Agreement \\
\hline Volunteer recruitment & $100.0 \%$ \\
\hline Member retention & $100.0 \%$ \\
\hline Competition with other activities & $100.0 \%$ \\
\hline Lack of adult engagement in youth's 4-H involvement & $92.9 \%$ \\
\hline Increased volunteer responsibility & $85.7 \%$ \\
\hline Budget challenges & $85.7 \%$ \\
\hline Time commitment of youth & $78.6 \%$ \\
\hline Marketing and promotion & $78.6 \%$ \\
\hline Outdated image of program & $71.4 \%$ \\
\hline Lack of 4-H-school partnerships & $71.4 \%$ \\
\hline Lack of professional support and leadership for educators & $57.1 \%$ \\
\hline Family financial barriers & $57.1 \%$ \\
\hline Enrollment barriers & $57.1 \%$ \\
\hline Outdated programming & $42.9 \%$ \\
\hline Adhering to National 4-H initiatives & $21.4 \%$ \\
\hline
\end{tabular}

\section{Round 3}

In Round 3, panelists were asked to rank their level of agreement with challenge statements that received $51 \%$ to $74 \%$ agreement in Round 2 . The purpose of the third round was to further seek consensus on remaining items (see Tables 3 and 4).

Table 3. Challenge Statements and Agreement Percentages in Round 3: Panel 1

\section{Challenges facing the Oklahoma 4-H Program in the next 5 years}

Volunteer retention

Increased workload on educators

Professional development of early-career educators
$\%$ Agreement

$92.3 \%$

$92.3 \%$

$61.5 \%$ 
Journal of Youth Development | http://jyd.pitt.edu/ | Vol. 14 Issue 3 DOI 10.5195/jyd.2019.740 Delphi Technique to Identify Program Challenges

Table 4. Challenge Statements and Agreement Percentages in Round 3: Panel 2

\begin{tabular}{|l|c|}
\hline Challenges facing the Oklahoma 4-H Program in the next 5 years & \% Agreement \\
\hline Lack of 4-H-school partnerships & $84.6 \%$ \\
\hline Outdated image of program & $69.2 \%$ \\
\hline Lack of professional development and leadership for educators & $58.8 \%$ \\
\hline Enrollment barriers & $46.2 \%$ \\
\hline Family financial barriers & $30.8 \%$ \\
\hline
\end{tabular}

\section{Panel Findings Comparison}

After three rounds, Extension educator and volunteer panelists identified 11 challenges and the parent panelists identified nine challenges facing the Oklahoma 4-H program in the next 5 years (See Table 5).

Table 5. Comparison of the Challenge Statements Identified by Both Panels That Reached Consensus After Three Rounds

\begin{tabular}{|l|c|c|}
\hline Challenges identified by panels & $\begin{array}{l}\text { Panel 1 } \\
\text { \% agreement }\end{array}$ & $\begin{array}{l}\text { Panel 2 } \\
\text { \% agreement }\end{array}$ \\
\hline Volunteer recruitment & $92.3 \%$ & $100.0 \%$ \\
\hline Member retention & $92.3 \%$ & $100.0 \%$ \\
\hline Competition with other activities & $92.3 \%$ & $100.0 \%$ \\
\hline Lack of adult engagement in youth's 4-H involvement & $92.3 \%$ & $92.9 \%$ \\
\hline Budget challenges & $92.3 \%$ & $85.7 \%$ \\
\hline Marketing and promotion & $92.3 \%$ & $78.6 \%$ \\
\hline Lack of 4-H-school partnerships & $84.6 \%$ & $84.6 \%$ \\
\hline Time commitment of youth & $76.9 \%$ & $78.6 \%$ \\
\hline Volunteer retention & $92.3 \%$ & \\
\hline Increased workload on educators & $92.3 \%$ & \\
\hline Enrollment barriers & $92.3 \%$ & \\
\hline Increased volunteer responsibility & & $85.7 \%$ \\
\hline
\end{tabular}

Both panels reached consensus on eight identical statements reflecting challenges to Oklahoma 4-H: volunteer recruitment, member retention, competition with other activities, lack of adult 


\section{Delphi Technique to Identify Program Challenges}

engagement in youth's 4-H involvement, budget challenges, marketing and promotion, lack of 4-H-school partnerships, and time commitment of youth.

Three distinct challenges were identified by the Extension educator and volunteer panel: volunteer retention, increased workload on educators, and enrollment barriers. The parent panel also identified increased volunteer responsibility as a challenge different from the Extension educator and volunteer panel.

Professional development of early-career educators and lack of professional support and leadership for educators were two similar challenges identified by both panels. However, these items did not reach consensus. Additionally, enrollment barriers reached consensus by the Extension educator and volunteer panel but did not reach consensus with the parent panel.

\section{Implications for Youth Development}

The purpose of this study was to determine challenges facing the Oklahoma 4-H program in the next 5 years as perceived by two expert panels. The eight identified challenges by both panels have implications for practitioners engaged in many youth development organizations. To that end, the conclusions and recommendations have a clear emphasis on the 4- $\mathrm{H}$ organization in Oklahoma.

The Extension educator and volunteer panel identified 11 challenges and the parent panel identified nine challenges facing Oklahoma 4-H. Of those items, eight identical challenge statements were identified by both panels. According to both expert panels, Oklahoma 4-H needs to focus on addressing these primary challenges:

1. Volunteer recruitment

2. Marketing and promotion

3. Lack of adult engagement in youth's 4-H involvement

4. Member retention

5. Time commitment of youth

6. Competition with other activities

7. Lack of 4-H-school partnerships

8. Budget challenges 


\section{Delphi Technique to Identify Program Challenges}

\section{Volunteer Recruitment}

The panels understood the importance of volunteers to the success and delivery of 4-H programs, as they indicated recruiting volunteers should be a priority for Oklahoma 4-H. This finding applies to other youth development organizations. In the context of school-based agricultural education, volunteer recruitment could be further enhanced if agricultural teachers were better equipped to recruit, retain, and reward volunteers to assist with program delivery. As Borden et al. (2014) asserted, volunteer recruitment is a considerable challenge to be addressed.

\section{Marketing and Promotion}

Addressing the challenge of marketing and promotion is another priority, according to the panels. The literature reveals a need for $4-\mathrm{H}$ programs to improve marketing efforts to promote an inclusive organization and help the public understand the depth of 4-H (Cano \& Bankston, 1992; Ferarri, Hogue, \& Scheer, 2004; McKee, Talbert, \& Barkman, 2002). Increasing and improving marketing efforts can serve multiple purposes in Oklahoma 4-H, such as recruiting members and volunteers and overcoming the agricultural stereotype associated with 4- $\mathrm{H}$, which can attract more diverse audiences.

Inclusivity has become a focus for youth organizations (Christens \& Dolan, 2011). The Boy Scouts of America (BSA) and the National FFA Organization both have focused on marketing and programing to promote a more diverse and inclusive environment for the youth and adult leaders who represent the organizations. Findings from this study reinforce youth development organizations' need to be mindful of their membership and realize the importance of their marketing and promotional efforts.

Extension educators are the face of the 4-H program within their counties. Therefore, educators should prioritize promoting their $4-\mathrm{H}$ programs as a job responsibility. Marketing efforts should emphasize the variety of opportunities and benefits within Oklahoma 4- $\mathrm{H}$, including project areas, awards and recognition, and state and national trips to attract youth from all backgrounds and settings.

\section{Lack of Adult Engagement in Youth's 4-H Involvement}

Our findings reveal educators, volunteers, and parents believe adult involvement in youth's 4-H career is crucial for a positive experience. This aligns with previous studies reporting the 


\section{Delphi Technique to Identify Program Challenges}

importance of parental involvement (Radhakrishna, Foley, Ingram, \& Ewing, 2013; Wingenbach, Meighan, Lawrence, Gartin, \& Woloshuk, 1999). However, with the busy lifestyles of today's families, it can be difficult to expect parents to fully commit to their children's activities. Youth organizations such as 4-H; FFA; BSA; Family, Career and Community Leaders of America (FCCLA); and youth sport leagues hold the potential to provide a venue for adult, parental and family involvement to enhance positive youth development.

Solidifying a volunteer base within the organization can help address the issue of 4-H youth who do not have parental support in their 4-H experiences, as positive volunteer relationships can impact youth's involvement in the organization. (Wingenbach et al., 1999). Understanding parents' and volunteers' needs and interests is important to engage them in the organization. Further, recruiting parents to take a more active role in the 4- $\mathrm{H}$ program by serving as volunteers can potentially fulfill a dual purpose of increasing the volunteer base and incorporating adult engagement in youth's 4-H experiences.

\section{Member Retention and Time Commitment of Youth}

Loss of membership was noted by the panels as a challenge facing the Oklahoma 4-H program. Members must be fully engaged in the program in order to experience the benefits of positive youth development. Encouraging youth to commit the time in $4-\mathrm{H}$ to receive the benefits such as gaining valuable life skills can aid in retaining youth throughout their adolescence.

Panelists indicated Oklahoma 4-H must offer a variety of life skill-building experiences to retain its members. This finding is similar to previous research stating youth participate in 4-H activities based on their desire to develop skills such as public speaking and leadership (Gill, Ewing, \& Bruce, 2010).

\section{Competition with Other Activities}

Youth have a wide selection of activities in which to participate. "Even with competing and/or complementary activities, 4-H continues to offer unique opportunities that are appealing to a segment of the youth population" (Van Horn et al., 1999). Offering a range of activities better suited to members' interests and needs will prevent youth venturing to other activities and organizations. 


\section{Delphi Technique to Identify Program Challenges}

\section{Lack of 4-H/School Partnerships}

Panelists identified a need for more 4-H-school partnerships. Forming 4-H partnerships with public school systems can result in increased youth involvement, as 4-H activities such as school enrichment can pique students' interest to participate in 4-H activities outside of school. This finding supports Van Horn et al. (1999), who reported school-based programming can generate more awareness of 4-H. Establishing a presence within schools can generate awareness of Oklahoma 4-H, resulting in increased membership. This finding holds true with any youth development organization.

\section{Budget Challenges}

Budgetary shortfalls can have serious repercussions to the Oklahoma 4-H program if not addressed. The value of 4-H programs should be documented in times of budget shortfalls (Radhakrishna \& Sinasky, 2005). Many state legislators are unfamiliar with the organization into which 4-H has evolved. Oklahoma 4-H should prioritize demonstrating the benefits and impacts of its diverse programs to state policy leaders and decision makers to increase funds invested in Extension. Sharing impact reports and personal success stories from youth members, families, and alumni also can be beneficial to articulate the influence 4- $\mathrm{H}$ makes in youth's lives.

Further research should be conducted on each of the identified challenges facing all youth development organizations. Specifically, these challenges should be addressed to improve the Oklahoma 4-H Youth Development Program.

\section{Conclusion}

This study is an in-depth look at one of the 50 states' $4-\mathrm{H}$ programs. Our findings are relevant in other locations. The commonality of findings among the 4-H educators (4-H agents), 4-H volunteers, and 4-H parents illustrates that the challenges 4- $\mathrm{H}$ faces from different angles, perspectives, and levels are very similar. Each finding in this study is supported by past research, further solidifying the validity of our results. These results can be extended to other youth development organizations through the practitioners' analysis and application to their specific organization.

Youth practitioners and those charged with youth programming should consider these challenges as they evaluate vision and mission statements, bylaws, or other governing documents that inform practice. It is ultimately up to the reader of this study to apply these 


\section{Delphi Technique to Identify Program Challenges}

findings and implications to their location, situation, or youth development organization. This study could be replicated in any state to confirm the challenges facing $4-\mathrm{H}$ or other youth development programs. Findings of this study and future studies should be shared with Extension stakeholders and youth development professionals to promote the discussion of solutions to the challenges identified. This research study indicates these findings may be widespread and affect other locations beyond Oklahoma; including other youth development and youth-serving organizations.

\section{References}

Arnold, M. E., Dolenc, B. J., Rennekamp, R. A. (2009). An assessment of 4-H volunteer experience: Implications for building positive youth development capacity. Journal of Extension, 475 ). Retrieved from https://joe.org/joe/2009october/a7.php

Astroth, K. A. (2007). Making the best better: 4-H staffing patterns and trends in the largest professional network in the nation. Journal of Youth Development, 2(2). Retrieved from https://jyd.pitt.edu/ojs/jyd/article/view/343/329

Borden, L. M., Perkins, D. F., Hawkey, K. (2014). 4-H youth development: The past, present, and the future. Journal of Extension, 52(4). Retrieved from https://www.joe.org/joe/2014august/comm1.php

Boyd, B. L., Herring, D. R., \& Briers, G. E. (1992). Developing life skills in youth. Journal of Extension, 30(4). Retrieved from https://www.joe.org/joe/1992winter/a4.php

Brady, S. R. (2015). Utilizing and adapting the Delphi method for use in qualitative research. International Journal of Qualitative Methods, 14(5), 1-6. doi:10.1177/1609406915621381

Brady, S. R. (2016). Utilizing the Delphi method in community based participatory research. In L. Jason \& D. Glenwick (Eds.), Handbook of Methodological Approaches to Community-Based Research: Qualitative, Quantitative, and Mixed Methods. New York: Oxford Press.

Brooks, K. W. (1979). Delphi technique: Expanding applications. North Central Association Quarterly, 54(3). 377-385.

Cano, J., \& Bankston, J. (1992). Factors which influence participation and non-participation of ethnic minority youth in Ohio 4-H programs. Journal of Agricultural Education, 33(1), 23-29. doi:10.5032/jae.1992.01023

Christens, B. D., \& Dolan, T. (2011). Interweaving Youth Development, Community Development, and Social Change Through Youth Organizing. Youth \& Society, 43(2), 528-548. https://doi.org/10.1177/0044118X10383647

Culp, K., \& Schwartz, V. J. (1999). Recognizing tenured 4-H adult volunteers. Journal of Agricultural Education, 40(2), 38-45. doi:10.5032/jae.1999.02038 
Journal of Youth Development | http://jyd.pitt.edu/ | Vol. 14 Issue 3 DOI 10.5195/jyd.2019.740

\section{Delphi Technique to Identify Program Challenges}

Dalkey, N. C., \& Helmer, O. (1963). An experimental application of the Delphi method through the use of experts. Management Science, $9(3), 458-467$.

Dalkey, N. C., Rourke, D. L., Lewis, R., \& Snyder, D. (1972). Studies in the quality of life. Lexington, MA: Lexington Books.

Feldhues, K., \& Tanner, T. (2017). Show me the money: Impact of county funding on retention rates for Extension educators. Journal of Extension, 55(2). Retrieved from https://www.joe.org/joe/2017april/rb3.php

Ferrari, T. M., Hogue, C. A., \& Scheer, S. D. (2004). Parents' perceptions of life skills development in the 4-H Cloverbud program. Journal of Extension, 42(3). Retrieved from https://www.joe.org/joe/2004june/rb6.php

Franklin, K. K., \& Hart, J. K. (2007). Idea generation and exploration: Benefits and limitations of the policy Delphi research method. Innovative Higher Education, 31(4). Retrieved from https://link.springer.com/article/10.1007/s10755-006-9022-8

Gill, B. E., Ewing, J. C., Bruce, J. A. (2010). Factors affecting teen involvement in Pennsylvania 4-H programming. Journal of Extension, 48(2). Retrieved from https://www.joe.org/joe/2010april/a7.php

Hanafin, S. (2004). Review of literature on the Delphi Technique. Dublin: National Children's Office.

Harder, A., Gouldthorpe, J., Goodwin, J. (2015). Exploring organizational factors related to Extension employee burnout. Journal of Extension, 53(2). Retrieved from https://www.joe.org/joe/2015april/a2.php

Hsu, C., \& Sandford, B. A. (1998). The Delphi Technique: Making sense of consensus. Practical Assessment, Research \& Evaluation, 14(3), 215-237. doi:10.1080/13504620802148881

Linstone, H. A., \& Turoff, M. (Eds.). (1975). The Delphi method: Techniques and applications. Reading, MA: Addison-Wesley Publishing.

Ludwig, B. (1997). Predicting the future: Have you considered using the Delphi methodology? Journal of Extension, 35(5). Retrieved from https://www.joe.org/joe/1997october/tt2.php

Martin, A. G., \& Frick, M. J. (1998). The Delphi technique: An informal history of its use in agricultural education research since 1984. Journal of Agricultural Education, 39(1), 73-79. doi:10.5032/jae.1998.01073

Mayfield, C. A., Wingenbach, G. J., \& Chalmers, D. R. (2005). Assessing stakeholder needs: Delphi meets the internet. Journal of Extension, 43(3). Retrieved from https://www.joe.org/joe/2005june/iw1.php

McKee, R. K., Talbert, B. A., Barkman, S. J. (2002). The challenges associated with change in 4-H/youth development. Journal of Extension, $40(2)$. Retrieved from https://www.joe.org/joe/2002april/a5.php

National 4-H Council. (2018). What is 4-H? Retrieved from http://www.4-h.org 


\section{Delphi Technique to Identify Program Challenges}

Oklahoma 4-H. (2018b). Oklahoma 4-H Fast Facts. Retrieved from http://4h.okstate.edu/literaturelinks/marketing-resources/marketing-resources

Oklahoma 4-H. (2018a). Projects. Retrieved from www.okstate.edu/project

Radhakrishna, R., Foley, C., Ingram, P., \& Ewing, J. C. (2013). Effectiveness of the 4-H program as perceived by parents of 4-H participants. Journal of Extension, 51(4). Retrieved from https://www.joe.org/joe/2013august/rb8.php

Radhakrishna, R. B., \& Sinasky, M. (2005). 4-H experiences contributing to leadership and personal development of 4-H alumni. Journal of Extension, 43(6). Retrieved from https://www.joe.org/joe/2005december/rb2.php

Ramsey, J. W. (2009). Identifying entry-level skills expected by agricultural industry experts and determining teachers' perceptions on whether they are being learned through students' participation in the supervised agricultural experience component of the secondary agricultural education program: A two-panel Delphi study. (Doctoral dissertation). Available from ProQuest Dissertations and These Database. (UMI No. 3390968).

Reck, F. M. (1951). The 4-H Story. Ames, Iowa: National 4-H Service Committee and the Iowa State University Press.

Rousan, L. M., \& Henderson, J. L. (1996). Agent turnover in Ohio State University Extension. Journal of Agricultural Education, 372), 56-62. doi:10.5032/jae.1996.02056

Shinn, G. C., Wingenbach, G. J., Lindner, J. R., Briers, G. E., \& Baker, M. (2009). Redefining agricultural and extension education as a field of study: Consensus of fifteen engaged international scholars. Journal of International Agricultural and Extension Education, 16(1), 73-88. doi:10.5191/jiaee.2009.16106

Smalley, S. W., \& Retallick, M. S. (2011). Purposes, activities, and documentation of early field experience in agricultural teacher education: A national Delphi study. Journal of Agricultural Education, 52(3), 100-109. doi:10.5032/jae.2011.03100

Stewart, J., \& Scheihing, C. (2010). Oklahoma 4-H: Generations of Clovers. Virginia Beach, VA: The Donning Company Publishers.

Strong, R., \& Harder, A. (2009). Implications of maintenance and motivation factors on Extension agent turnover. Journal of Extension, $4 \pi 1$ ). Retrieved from https://www.joe.org/joe/2009february/a2.php

Van Horn, B. E., Flanagan, C. A., Thomson, J. S. (1999). Changes and challenges in 4-H (Part 2). Journal of Extension, 3Л1). Retrieved from https://www.joe.org/joe/1999february/comm1.php

Wingenbach, G. J., Meighan, T., Lawrence, L. D., Gartin, S. A., Woloshuk., J. (1999). Associated factors in recruitment and retention of 4-H members in West Virginia. Journal of Agricultural Education, 4O(1), 23-29. doi:10.5032/jae.1999.01023 